\title{
On the Construction of Humanistic Quality Curriculum System in Application-Oriented Universities to Push forward the Reform of the Humanities Curriculum and Improve the Humanistic Qualities of College Students

\author{
Li Fang ${ }^{1}$, Dong Junfang ${ }^{2 *}$
}

1,2 Wuhan Business University, Wuhan 430056 China

*Corresponding author: Dong Junfang Email: li_fang02@163.com

Keywords: Humanistic quality, Humanistic quality education course

Abstract. Humanistic quality education is an indispensable part of higher education. It accompanied the whole process of talent cultivation and the whole career of college students. The current curriculum of humanistic quality in applied universities attaches great importance to professional disciplines, but education is not effective enough. Its evaluation system is too simple to reflect the students' performance. This leads to a lack of humanistic quality in college students. This paper analyzes the significance of education course on humanistic quality in new applied universities, the problems faced, the strategy of course system construction and the method of effect evaluation. This paper hopes to build an education course system with distinct levels, reasonable structure and interdisciplinary integration, combine the obvious course with the hidden course, carry forward the campus culture, enrich the personnel training mode, and improve the humanistic quality of college students.

\section{Introduction}

Since the 1990s, China's higher education system has strengthened the humanistic quality education, thus improving the humanistic quality of college students. We pay more and more attention to cultivating the humanistic spirit of college students. The construction of education curriculum system of humanistic quality is an effective way to implement education in institutions of higher learning. Some scholars believe that "the influence of humanistic courses on the humanistic spirit of college students is not all-powerful, but it is of great practical significance to enrich the ideological resources of humanistic courses, improve the quality of humanistic courses, arouse the attention of universities on humanistic spirits and clarify people's misunderstanding of humanistic courses." [1] Therefore, the comprehensive and interdisciplinary adjustment of professional education must be strengthened according to the thought and purpose of education. We should take the humanities quality education course as the basic course of the whole course system and incorporate it into the important curriculum system of colleges and universities.

\section{Significance and Purpose of Education Curriculum Design for Humanistic Quality}

Education is both a knowledge system and a value system. The object of its study involves not only the social and cultural fields of human beings, but also the spiritual and value fields of human beings. Its education goal is not only to improve students' cultural literacy, but also to equip them with basic knowledge of literature, history and philosophy. More importantly, it emphasizes the cultivation and shaping of people's character and personality, and strives to make the educatee change the external cultural attainment and moral standards into its own emotional, will, moral and behavioral norms, and help the educatee form a correct world view, outlook on life and values.

2.1 Building the education curriculum system of humanistic quality can provide value guidance for the education of application-oriented universities.

Education, an applied undergraduate major, mainly teaches students professional knowledge and skills. Professional knowledge mainly includes basic science, comprehensive knowledge, technical connotation, humanities and social sciences, etc. Professional skills mainly refer to professional theory operation, 
professional practical operation, professional judgment, ability to provide professional information and communication. There are a lot of education factors in the aspects of knowledge transfer, ability training and consciousness cultivation in professional teaching. Therefore, professional teaching must be value oriented with humanistic quality education.

2.2 Improve the student's employment and entrepreneurship capability.

The goal of training applied undergraduates is to cultivate high-quality skilled talents with innovative spirit and practical ability. The construction of humanistic quality education course system is conducive to cultivating students' good sentiment and sound personality, enabling them to be influenced by character and sentiment unconsciously, cultivating their good professional ethics and social responsibility, and improving their employment and entrepreneurship ability.

\section{Problems in the Curriculum Setting of Humanistic Quality in Application-Oriented Universities}

In many application-oriented universities, education courses are more as a supplement to the current curriculum system. The establishment of the original curriculum system has exposed many defects that do not adapt to the development of modern society.

\subsection{The curriculum is lack of scientific argumentation and is arbitrary}

The setting of education elective courses for humanistic quality in most universities depends on the interest of teachers. Most of the courses are not scientifically verified, and involve narrow and single fields, failing to form a universal reasonable, scientific, perfect and distinctive education curriculum system for humanistic quality.

\subsection{Course types and periods are insufficient and the course proportion is not balanced}

The courses offered by education of humanistic quality have fewer classes and periods, and the credits of humanistic quality courses take a low proportion in the total credits taken by college students. Some college students take humanities courses not out of their own interests and the need to improve quality, but the requirements of school credit. In addition, the insufficiency of humanities elective courses and the imbalance of proportion seriously affect the comprehensive development of college students, which is not conducive to talent cultivation.

\subsection{The connection between courses is weak and we only focus on knowledge teaching not on ability cultivate}

Many universities often adopt the method of "embedding" the education course of humanistic quality into the original teaching system, resulting in the lack of organic connection between education course of humanistic quality and the imbalance of structure. The teaching content and curriculum system of humanistic quality courses still pay too much attention to the teaching of specialized knowledge, and there is a tendency to emphasize on the teaching of knowledge, and ignore the cultivation of ability and the improvement of quality. Therefore, humanistic quality education becomes humanistic knowledge education. [2]

\subsection{Insufficient professional ability of teachers}

At present, the humanities quality courses in most universities are short of full-time teachers. Some teachers do not pay enough attention to the humanities quality education courses and do not prepare enough lessons. At the same time, humanistic quality courses are generally taught in large classrooms, with a large number of students, and classroom activities and teacher-student interaction are difficult to carry out.

\subsection{The examination method is too loose, and college students do not pay enough attention to it}

The examination method of education course of humanistic quality is mostly inspection form, because the examination method is not strict and the learning effect cannot be identified, which leads to the insufficient attention paid to education course of humanistic quality by college students, who regard education course of humanistic quality as the course gathering credits. Humanistic quality education is mostly carried out in the form of public elective courses or large courses. 


\section{Construction of Education Curriculum System of Humanistic Quality in Universities}

According to the humanistic quality education training objectives, the design of the humanistic quality curriculum system should be around the ideological and political education, humanism quality education basic cultural quality education, professional association, such as the three core contents, literature, history, philosophy, art, psychology, law, economics, sociology, political science, humanities and social science knowledge by setting up various related courses throughout the inside and outside class teaching process, fusion, to infiltrate the education teaching activities, the formation of explicit and implicit curriculum system more perfect. [3] it is divided into three parts: subject course system, activity course system and environment course system.

\subsection{Subject Curriculum system.}

In the long-term theoretical and practical exploration of Chinese universities, the curriculum system of humanistic quality should contain at least 7 modules, namely, education of Chinese and western culture (literature), education of art, education of philosophy, education of economy and management, education of mental health, education of language and integrated education. In each module, one or two core courses are compulsory, and professional selective courses and optional courses are set according to the needs, which fully cover the education requirements for university students' humanistic quality, so as to achieve the basic goal of education, and help students acquire more systematic humanistic knowledge and improve humanistic quality.

For example:

(a) Chinese and western culture (literature) education is to strengthen college students' cognition of Chinese and western culture and give full play to the unique humanistic advantages and aesthetic education functions of literature courses;

(b) Art education is to cultivate students' good moral sentiment.

(c) Philosophy education is to cultivate college students' ability to gain insight into the society and understand the nature of things.

(d) Economy and management education aim to enable college students to master necessary basic knowledge of economics and management to adapt to the needs of economic and social development and sustainable development.

(e) Psychological and health education is to cultivate students' good mentality and healthy psychology and cultivate students' innovative personality.

(f) Language education focuses on the comprehensive application of written language and oral language, and focuses on the cultivation of college students' skills and skills in doing and doing things;

(g) Integrated education to give guidance to college students in study, life and practice.

\subsection{Activity curriculum system.}

Although classroom teaching is the main channel for systematically teaching humanistic knowledge, the number of courses for students is limited due to the limitation of schooling system and total time. According to the features and orientation of the school, combined with the talent training objectives and discipline features of the school and education resources, the hidden classroom teaching activities are organized and planned, which is of positive significance to the cultivation of humanistic quality of college students. The hidden curriculum system includes social practice, humanistic academic lectures and campus cultural activities.

\subsubsection{Social practice activities}

Social practice activities mainly rely on science and technology, culture, health and other activities, and engage in social services such as social investigation, publicity of law popularization, supporting education and literacy, poverty alleviation, publicity of popular science and voluntary services. College students can not only consolidate and deepen their knowledge and expand their scope of knowledge through such activities as summer social practice, young volunteers and community service, but more importantly, they can perform, education and improve themselves in various social practice activities. 


\subsubsection{Humanities academic lecture}

The relevant departments of the school will hold lectures on humanities and academic subjects from time to time, such as lectures on traditional culture and career planning. Creating a strong academic atmosphere on campus has the effect of "polishing things like sound" on cultivating the humanistic spirit of college students.

\subsubsection{Campus cultural activities}

Abundant campus cultural activities enable college students to realize and improve in activities and actions. Campus culture is not a simple lecture and inculcation, nor is the teaching of pure knowledge but the edification of environmental atmosphere. College students can use the library, propaganda column, campus network and other cultural positions to participate in various campus cultural activities to enrich humanistic knowledge.

\subsection{Environmental curriculum system}

Humanistic environment course is also an important content and link of the education course system of humanistic quality. It plays an extensive, ancient and profound role of education in an imperceptible way. Education environment course includes three aspects:

\subsubsection{Physical environment.}

It mainly includes various buildings and facilities, teaching and scientific research equipment, books and materials, cultural window, campus road, campus cultural attractions design and beautification, etc. The natural environment, cultural facilities and school buildings of the campus are important components of the humanities and academic atmosphere of modern universities, and are the explicit courses of the school.

\subsubsection{Spiritual environment.}

Such as school history school motto, cultural atmosphere, academic atmosphere, values and so on. The spiritual environment is the deep core of the cultural environment education environmental curriculum and an important hidden curriculum of the school. The environmental courses of humanistic quality and the humanistic atmosphere formed by them have an education function that cannot be ignored for the ideal belief, value orientation, moral sentiment and aesthetic concept of college students.

4.3.3 Institutional environment.

Such as policy guarantee, organization guarantee, class guarantee, evaluation mechanism and so on. A sound institutional environment is an important support for the implementation of education.

\section{Evaluation System of Education Curriculum for Humanistic Quality in Colleges and Universities}

Strengthening the evaluation and management of humanistic quality courses is the leverage of education implementation of humanistic quality courses. We should strive to establish and form a diversified evaluation system in and out of class, in and out of school, so as to promote learning through evaluation.

\subsection{Improve the curriculum management system}

The humanistic quality education is included in the teaching management, student work management and teacher performance evaluation management system. Strengthen the supervision and guidance on the teaching process, teaching content, teaching quality and performance evaluation of the teachers of the humanities education course. Set up specific management methods for humanities elective courses, such as requirements, curriculum setting, management of class hours and credits, curriculum assessment and score record, and continuously improve the actual effect of education.

\subsection{Credit system}

Scientific planning credit structure, in the compulsory, limited and optional credit, stipulate the minimum credits of humanities quality courses. At the same time, the content of humanistic quality evaluation of college students should be improved, the education activity of cultural quality should be included into the extracurricular credit management of college students, and the achievement and 
performance of college students in participating in various cultural activities and social practice should be taken as the evaluation basis of humanistic quality education and included into corresponding credits. The implementation of extracurricular credits will play a good role in restricting and motivating the formation of college students' good thinking mode and behavior norms and become an important aspect of dynamic evaluation.

\subsection{Construct diversified evaluation methods}

The education course evaluation of humanistic quality should adopt different evaluation methods and methods for different objects. For example, it can be evaluated in various ways, such as performance, thesis, review, case analysis, investigation report, and students' lectures, which can positively promote the development of humanistic quality education course.

\section{Conclusion}

Humanistic quality education is an indispensable part of higher education. It accompanied the whole process of talent cultivation and the whole career of college students. It is imperative to reform humanistic quality courses in new applied universities. it is worth our joint discussion that how to break through the existing subject course system, combine the subject course system, activity course system and environment course system closely, build the humanities course system with the characteristics of the application-oriented universities, carry out humanistic quality education in a planned way, and improve the effectiveness of education.

\section{Acknowledgment}

This paper is a stage research result of the teaching and research project of Wuhan business school in 2016: 'Research on reform and innovation of humanistic quality courses in application-oriented universities in the context of mobile Internet -- a case study of Wuhan business school' (project number: 2016Y001) and 2017 Wuhan education science "13th five-year" plan project: 'An empirical study on cultivating humanistic quality of university students in Wuhan from the perspective of reading' (project number: 2017C157)

\section{Reference}

[1] Li Hui, Lin Yiping. Humanistic interpretation and regression of university spirit [J]. Education study of higher engineering, 2004, (1): 66

[2] Li Minggao. Construction of education course system for humanistic quality in university of science and engineering [J]. Journal of Huaiyin normal university, 2008, (3): 407

[3] Wang Li, Fu Xinhe. Analysis on the curricul um system design of education in agricultural colleges [J]. Academic theory, 2010, (6): 202 